\title{
Determinants of Caulerpa racemosa distribution in the north-western Mediterranean
}

\author{
Fabio Bulleri ${ }^{1,2, *}$, Tommaso Alestra ${ }^{1}$, Giulia Ceccherelli ${ }^{2}$, Laura Tamburello ${ }^{1}$, \\ Stefania Pinna ${ }^{2}$, Nicola Sechi ${ }^{2}$, Lisandro Benedetti-Cecchi ${ }^{1}$ \\ ${ }^{1}$ Dipartimento di Biologia, Università di Pisa, CoNISMa, Via Derna 1, 56126 Pisa, Italy \\ ${ }^{2}$ Dipartimento di Science Botaniche, Ecologiche e Geologiche, Università di Sassari, Via Piandanna 4, 07100 Sassari, Italy
}

\begin{abstract}
Predicting community susceptibility to invasion has become a priority for preserving biodiversity. We tested the hypothesis that the occurrence and abundance of the seaweed Caulerpa racemosa in the north-western (NW) Mediterranean would increase with increasing levels of human disturbance. Data from a survey encompassing areas subjected to different human influences (i.e. from urbanized to protected areas) were fitted by means of generalized linear mixed models, including descriptors of habitats and communities. The incidence of occurrence of C. racemosa was greater on urban than extra-urban or protected reefs, along the coast of Tuscany and NW Sardinia, respectively. Within the Marine Protected Area of Capraia Island (Tuscan Archipelago), the probability of detecting C. racemosa did not vary according to the degree of protection (partial versus total). Human influence was, however, a poor predictor of the seaweed cover. At the seascape level, C. racemosa was more widely spread within degraded (i.e. Posidonia oceanica dead matte or algal turfs) than in better preserved habitats (i.e. canopy-forming macroalgae or $P$. oceanica seagrass meadows). At a smaller spatial scale, the presence of the seaweed was positively correlated to the diversity of macroalgae and negatively to that of sessile invertebrates. These results suggest that C. racemosa can take advantage of habitat degradation. Thus, predicting invasion scenarios requires a thorough knowledge of ecosystem structure, at a hierarchy of levels of biological organization (from the landscape to the assemblage) and detailed information on the nature and intensity of sources of disturbance and spatial scales at which they operate.
\end{abstract}

KEY WORDS: Biological invasion · Seaweeds • Benthic assemblage • Distribution pattern . Urbanization $\cdot$ Habitat degradation $\cdot$ MPA

\section{INTRODUCTION}

Despite the majority of introduced species failing to establish in new areas, devastating effects of exotics on the biodiversity and functioning of recipient ecosystems have been widely documented (Pimentel et al. 2001). Understanding the mechanisms regulating species invasions has, thus, become a pressing need to predict pathways of invasion and areas most susceptible to invasion.

Dispersal, colonization and establishment represent crucial phases of the invasion process (Kolar \& Lodge 2001, Richardson et al. 2007). Dispersal can vary according to propagule pressure (Von Holle \& Simberloff 2005) and the characteristics of the landscape being invaded (With 2002, Predick \& Turner 2008). Habitat configuration (i.e. size and spatial arrangement of patches of favourable or unfavourable habitats) can influence patterns of dispersal (With 2002, Hastings et al. 2005). Once a propagule has dispersed, its successful establishment depends on the physical attributes of the habitat (Byers 2002) and on the intensity of negative or positive interactions with extant species (Kennedy et al. 2002, Bulleri et al. 2008). Habitat quality includes physical characteristics of soil (seafloor), land (sea)-use history, or topography (e.g. 
Dupré \& Ehrlén 2002, Predick \& Turner 2008) and attributes of species forming the habitat (Bruno \& Bertness 2001). These can hinder or facilitate invader establishment either directly, by setting prevailing environmental conditions and/or consumer pressure or, indirectly, via the control they exert on associated communities. Thus, at a finer spatial scale, interactions with components of recipient communities represent the ultimate filter to invader establishment.

Multiple-scale control of the invasion process by natural features of the systems being invaded is, however, also influenced by human determinants (Ohlemüller et al. 2006, Diez et al. 2009). Prevailing environmental conditions (i.e. climate, geology) and human activities (either negative such as urbanization, agriculture/ aquaculture, oil extraction and mining, or positive such as the establishment of reserves or protected areas) set the regional scenario within which factors operating at finer scales, from the landscape to the habitat, down to the community, operate to regulate invasibility. Human influences and environmental factors are likely to interact, resulting in considerable variability in their net effect on invasion success (Davis et al. 2000, Diez et al. 2009). Thus, the effects of biotic or abiotic features of landscapes, habitats and communities on the ability of an exotic species to go through the different stages of invasion can be predicted to vary among areas subjected to different human influences. Given the patchwork nature of human activities, the development of models able to predict invader establishment and spread under different land-use scenarios is crucial for the management of natural systems.

The green macroalga Caulerpa racemosa is one of the most invasive seaweeds in the Mediterranean Sea (Piazzi et al. 2005). At the landscape level, patches dominated by dead Posidonia oceanica rhizomes (hereafter also referred to as dead matte) or algal turf stands have been reported to be highly vulnerable to invasion by this seaweed (Ruitton et al. 2005, Bulleri \& Benedetti-Cecchi 2008, Bulleri et al. 2009, 2010, Katsanevakis et al. 2010). Domination by canopy-forming algae (Bulleri et al. 2010) or intact seagrass meadows (Ceccherelli et al. 2000) seems, in contrast, to provide a barrier against invasion. Gaps within stands of canopyforming algae and seagrass beds are readily colonized by C. racemosa (Bulleri et al. 2010, Katsanevakis et al. 2010), but no empirical work has been done to assess the general role of habitat configuration in modulating its invasion success.

At a finer scale (i.e. community scale), both encrusting corallines and algal turfs have been demonstrated to facilitate the establishment and spread of Caulerpa racemosa, by enhancing the trapping and anchoring of fragments borne by wave action (Ceccherelli et al. 2002, Bulleri et al. 2009). Effects of resident algal assemblages can be, however, modulated by consumers. For instance, consumption of C. racemosa by fish (i.e. Spondyliosoma cantharus, Boops boops, Sarpa salpa and Diplodus sargus) (Ruitton et al. 2006, Box et al. 2009, Terlezzi et al. 2011, Tomas et al. 2011) and sea urchins has been widely documented (Ruitton et al. 2006, Bulleri et al. 2009).

Urban environments, being characterized by large propagule pressure and high levels of human disturbance, can be particularly susceptible to invasion (Glasby et al. 2006, Pickett et al. 2008, Clark \& Johnston 2009). Although invasion rates have been shown to increase along urban-to-rural gradients (Loewenstein \& Loewenstein 2005), little work has been done in marine habitats. Thus, we tested the hypothesis that the incidence of occurrence and abundance of Caulerpa racemosa increases with increasing levels of human disturbance, in the NW Mediterranean. In addition, we assessed whether the use of descriptors of habitat quality and configuration and of associated community structure can help to refine predictions of distribution and abundance of C. racemosa, in areas subjected to different human influences. Information available in the literature was used to select a set of environmental and biotic variables likely to play a role in determining patterns of distribution and abundance of C. racemosa.

\section{MATERIALS AND METHODS}

Study sites. An extensive survey was carried out at several sites along the coasts of Tuscany and northwestern (NW) Sardinia (Fig. 1). Such a regional approach (i.e. NW Mediterranean) enabled us to encompass sites exposed to a wide gradient of human activities, ranging from heavily urbanized or industrialized centres to totally protected areas (i.e. no entry zones in Marine Protected Areas [MPAs]).

The cities of Livorno and Rosignano Solvay (Fig. 1), located about $25 \mathrm{~km}$ apart along the coast of Tuscany, are considered pollution hotspots in European coastal waters (OECD 2002). Livorno has about 180000 inhabitants and hosts an oil refinery and one of the largest commercial ports of NW Italy. Rosignano Solvay is a smaller urban area, but industrial plants for the production of baking soda have been operating in the area since 1914. The shallow-water rocky assemblages in front of these cities are exposed to degraded physical conditions (e.g. reduced light penetration, inputs of organic and inorganic pollutants, enhanced rates of sedimentation) and severe disturbances (e.g. anchoring, harvesting, net trawling).

The quality of physical conditions is likely to improve, and the intensity of disturbance, to decrease progressively when moving away from city centres. In 


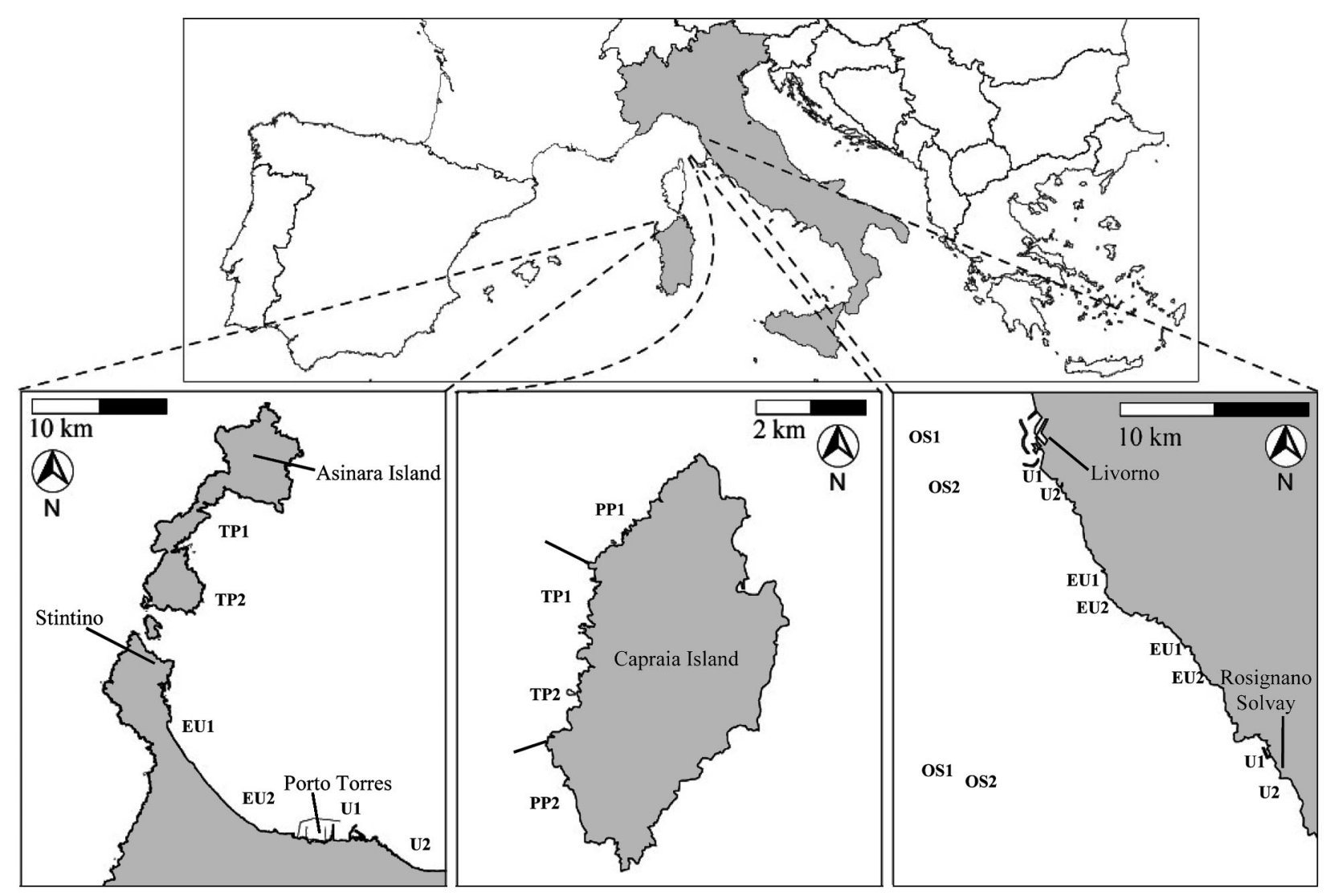

Fig. 1. Sites sampled in the NW Mediterranean: NW Sardinia, Capraia Island and coast of Tuscany (left, central and right panel, respectively). The 2 areas within each level of human influence locally available are indicated by capital letters: EU = extraurban; $\mathrm{OS}=$ off-shore; $\mathrm{PP}=$ partially protected; $\mathrm{TP}=$ totally protected; $\mathrm{U}=$ urban

particular, although characterized by intense boat traffic during summer months, off-shore reefs $(\sim 3 \mathrm{n}$ miles from the coast), in front of both the cities of Livorno (Secche della Meloria) and Rosignano Solvay (Secche di Vada), suffer less from land-based human activities (Fig. 1). Thus, levels of human disturbance can be thought to decrease when moving from urban to extraurban to off-shore reefs (hereafter also referred to as human influence). In order to achieve an operational definition of each of these levels of human disturbance, reefs $<3 \mathrm{~km}$ and $>8 \mathrm{~km}$ distant from main sources of pollution/disturbance (i.e. city centres, ports and industrial plants) were considered as urban and extraurban, respectively. These were the largest distances allowed by the geography of the study region, since extra-urban sites further distance apart would enter the shade of influence of other urban areas.

The same rationale was used to select reefs along the north-western tip of Sardinia (Fig. 1). Including the MPA of Asinara Island, it was possible to obtain data for reefs from which most impacting human activities, such as fishing, boating and anchoring, are not allowed (totally protected reefs). Invasion of Caulerpa racemosa on these protected reefs was compared to that on reefs in areas moderately (Stintino; hereafter referred to as extra-urban) or severely (the area of Porto Torres, in front of a major industrial development, including a commercial port, an oil refinery and a power plant; hereafter referred to as urban) impacted by human disturbances (Fig. 1). Finally, in order to further investigate the effects of the degree of protection from human activities on the ability of C. racemosa to get established, totally and partially protected reefs were compared along the coast of Capraia Island (Tuscan Archipelago, MPA established in 1989; Fig. 1).

Sampling design. Biotic variables: Two areas of $200 \times 200 \mathrm{~m}$ and $\sim 1 \mathrm{~km}$ apart, were randomly selected for each level of human influence at Livorno and Rosignano Solvay (urban, extra-urban and off-shore reefs), in NW Sardinia (urban, extra-urban and totally protected reefs) and at Capraia Island (partially and totally protected reefs; Fig. 1). Four transects, $30 \times 5 \mathrm{~m}$ wide, were randomly selected, 100s of metres apart, within each area. Along each transect, fish density was assessed by means of visual census techniques (Guidetti 2007). Fish settlers and recruits $(<2 \mathrm{~cm}$ total 
length, TL) were excluded from the study as their numerical contribution may greatly influence mean density values, while having no effect on benthic assemblages and, hence, on Caulerpa racemosa. The density of the sea urchins Paracentrotus lividus and Arbacia lixula was estimated by counting the individuals within the central $1 \mathrm{~m}$ wide strip along each transect. Urchins were treated as a guild, as their effects on C. racemosa have been previously shown not to differ (Bulleri et al. 2009). The relative proportion of different habitats was quantified by recording their linear extents along each transect. We could identify 7 gross habitats according to dominant habitat formers or prevalent features of the substratum: (1) seagrass meadows (Posidonia oceanica), (2) stands of canopy-forming (mostly Halopithys incurva and Cystoseira spp.) or (3) turf-forming macroalgae (mostly filamentous and articulated coralline forms), (4) barren grounds (species-poor patches dominated by encrusting corallines and deprived of erect macroalgae), (5) coralligenous assemblages (a hard substratum of biogenic origin that is mainly produced by the accumulation of calcareous encrusting algae growing in dim light conditions and hosting diverse macroalgal and invertebrate assemblages, as defined by Ballesteros 2006), (6) P. oceanica dead matte and (7) patches occupied by sand or gravel.

In addition, in order to account for potential effects of spatial arrangement (i.e. size and patchiness) of different habitats along each transect, we calculated the relative contagion index (RCI; Li \& Reynolds 1993). Each transect was divided into 300 cells of $10 \mathrm{~cm}$ length (our resolution for habitat mapping) and the RCI was calculated as: $1+\Sigma \Sigma P_{i j} \ln P_{i j} / 2 \ln m$, where $P_{i j}$ is the product between the probability of a cell to be occupied by habitat $i\left(P_{i}\right)$ and the probability to be adjacent to a cell occupied by habitat $j\left(P_{i} P_{i j}\right)$ and $m$ is the total number of habitats recorded in the transect. The RCI is a function of an evenness index, it ranges from 0 to 1 and measures the extent to which patch types are aggregated or interspersed. Higher values of contagion occur in the presence of few large, contiguous patches, whereas many small and scattered patches generate lower values. The RCI was preferred over other indexes of spatial patterns of landscapes since it enables comparisons of spatial configuration of landscapes regardless of how many patch types they contain (Li \& Reynolds 1993).

Along each transect, ten $20 \times 15 \mathrm{~cm}$ quadrats were randomly selected and photographed using a digital camera equipped with a waterproof case and a metal spacer and framer. When present, canopy-forming macroalgae or Posidonia oceanica were then removed to enable taking pictures of understorey assemblages. The percentage cover of macroalgae (including that of Caulerpa racemosa) and sessile invertebrates was estimated visually on a PC screen. A grid of 25 subquadrats was superimposed onto each image, a score from 0 to $4 \%$ was given to each taxon in each subquadrat and the percentage cover was obtained by summing over the entire set of sub-quadrats. Organisms could generally be identified to the species level, except for encrusting and filamentous algal forms, which were treated as morphological groups. Richness and total cover of invertebrates and macroalgae were then calculated for each replicate quadrat.

Environmental variables: At a scale of metres, topographic complexity was measured according to the chain method (Luckhurst \& Luckhurst 1978). One end of a $10 \mathrm{~m}$ long stainless-steel chain was randomly placed along the transect and allowed to sink to the bottom, while released in a straight line. Care was taken to ensure that the chain was conforming to the contour of the substratum. The relative difference between the real length of the chain and the measured distance between the 2 ends when conforming to the substratum provides a good estimate of complexity. This quantity was divided by the original length of the chain, in order to obtain values ranging from 0 to 1 , with smaller values indicating increasing complexity. Two measures of complexity were taken along each transect and subsequently averaged for analysis.

At a smaller spatial scale, topographic complexity was quantified by means of a plastic profile gauge, made of 140 plastic sliders of $1 \mathrm{~mm}$ thickness that were pressed firmly onto the substratum. Larger sized organisms were set aside in order to allow sliders to follow as accurately as possible the contour of the substratum. A picture of each profile was taken underwater using a digital camera. Images were then analyzed using the software ImageJ and its plug-in FracLac (free software developed by W. Rasband), and fractal dimension $(D)$ was estimated according to the box-counting method (Sugihara \& May 1990). The fractal dimension for a surface profile lies between 1 and 2 , with values $>1$ indicating greater degrees of surface complexity. We took 2 measures for each of the 10 quadrats that were randomly identified along each transect. Finally, depth was recorded at the centre of each quadrat.

In order to unconfound variation in space (i.e. due to prevailing human influences) with variation due to seasonality, all the sampling was carried out during late summer-early fall 2008, a period of the year at which Caulerpa racemosa peaks in abundance (Piazzi $\&$ Cinelli 1999). In addition, the sampling of transects within areas subjected to different human influences was randomized through time within each site (Tuscany, NW Sardinia and Capraia Island). Although potentially enhancing variation among replicated plots and transects within areas, our sampling schedule 
ensured that variation due to slightly different times of sampling was averaged out across areas subjected to different human influences.

Statistical analyses. Generalized linear mixedeffects models (GLMM) were used to model the relationship between patterns of distribution (estimated as presence/absence) or abundance (estimated as percentage cover) of Caulerpa racemosa and explanatory variables accounting for the effects of human influence, quality and configuration of habitat and community structure. Linear mixed-effects allow control of the non-independence of errors by modelling the covariance structure that is generated by the grouping of data or through the specification of various autocorrelation functions (Zuur et al. 2009). Our sampling design, including transects nested within areas (nested within sites for the data from the coast of Tuscany), generated data with a hierarchical spatial structure. These factors were, thus, included in the model (hereafter also referred to as the base model) as random effects, while human influence (coast of Tuscany: urban vs. extra-urban vs. off-shore reefs; NW Sardinia: urban vs. extraurban vs. totally protected reefs; Capraia Island: partially protected vs. totally protected reefs) was included as a fixed effect. In the analysis of data from the coast of Tuscany, the interaction Site $\times$ Human influence was initially included as a fixed effect. Deleting this interaction term did not cause a significant decrease in deviance, and it was therefore dropped from models.

Data from the different locations were analyzed separately, since the factor human influence had different levels for each of them. Analyses were run in R 2.10 ( $\mathrm{R}$ Development Core Team 2010), using the lmer function of the lme4 library in the R Package. A series of covariables accounting for the effects of quality and configuration of habitat and community structure were added to models (see Figs. 2 \& 3). These variables, except for depth, could be grossly divided into 5 main groups: human influence, habitat structure (herein intended as the physical features of habitat), habitat quality (herein intended as the biotic features of habitat), consumer or benthic assemblage structure (see Figs. $2 \& 3$ ). Prior to analysis, multicollinearity between predictor variables was checked by means of variance inflation factor analysis. In general, multicollinearity is considered low when the variance inflation factor (VIF) $<10$ (Crawley 2002).

In order to reduce multicollinearity, an unrotated principal component analysis (PCA) was performed on habitat variables. The first 3 ordination axes resulting from this procedure (hereafter referred to as PC1, PC2 and PC3) explained approximately 93 to $95 \%$ of the variation in the original habitat variables, across the 3 datasets (Table 1). These ordination axes are uncorrelated by definition, and scores were then used as predictor variables.

Presence/absence data for the coasts of Tuscany, NW Sardinia and Capraia Island were fit with a binomial error family and a logit link, using the Laplace method, since this is more reliable than penalized quasi-likelihood (Crawley 2007). We did not proceed in analyzing the cover of Caulerpa racemosa for NW Sardinia and Capraia Island datasets, since values recorded either inside or outside protected areas (except for the urban area in NW Sardinia) were generally low and, thus,

Table 1. Principal component analyses (PCAs) on descriptors of habitat quality, separately for comparisons: (A) among urban, extra-urban and off-shore reefs in Tuscany, (B) among urban, extra-urban and totally protected reefs in NW Sardinia, and (C) between partially and totally protected reefs at Capraia Island. Values are coefficients in the linear combination describing each axis. Only the first 3 axes are reported, as these explained a cumulative percentage of variation $>90 \%$ and were, thus, included as continuous variables in models. Scores of variables characterizing these axes are reported in bold to enhance the interpretation of their effects in the main analyses

\begin{tabular}{|lcrr|}
\hline Variable & PC1 & PC2 & PC3 \\
\hline (A) Coast of Tuscany & & & \\
Barren & 0.001 & -0.017 & 0.076 \\
Canopy-forming macroalgae & -0.009 & 0.016 & 0.002 \\
Turf-forming macroalgae & $\mathbf{- 0 . 7 7 0}$ & $\mathbf{- 0 . 3 5 1}$ & -0.253 \\
Dead Posidonia oceanica matte & 0.079 & 0.044 & $\mathbf{0 . 7 7 5}$ \\
Coralligenous & 0.038 & $\mathbf{0 . 8 0 2}$ & $\mathbf{- 0 . 3 8 3}$ \\
P. oceanica & $\mathbf{0 . 6 3 1}$ & $\mathbf{- 0 . 4 8 1}$ & $\mathbf{- 0 . 3 9 1}$ \\
Sedimentary bottoms & 0.030 & -0.013 & 0.174 \\
Cumulative percent of explained variation & 53.3 & 80.2 & 93.0 \\
(B) NW Sardinia & & & \\
Barren & 0.008 & -0.024 & 0.045 \\
Canopy-forming macroalgae & 0.216 & -0.442 & $\mathbf{0 . 7 0 9}$ \\
Turf-forming macroalgae & $\mathbf{- 0 . 7 6 6}$ & 0.380 & 0.113 \\
Dead P. oceanica matte & -0.006 & $\mathbf{- 0 . 5 0 8}$ & $-\mathbf{- 0 . 6 8 1}$ \\
P. oceanica & $\mathbf{0 . 6 0 3}$ & $\mathbf{0 . 6 3 3}$ & -0.123 \\
Sedimentary bottoms & -0.055 & -0.038 & -0.063 \\
Cumulative percent of explained variation & 44.8 & 72.4 & 94.8 \\
(C) Capraia Island & & & \\
Barren & -0.022 & 0.032 & -0.205 \\
Canopy-forming macroalgae & $\mathbf{0 . 8 4 8}$ & -0.095 & 0.325 \\
Turf-forming macroalgae & 0.068 & 0.128 & -0.202 \\
Dead P. oceanica matte & 0.045 & -0.045 & -0.122 \\
Coralligenous & $\mathbf{0 . 3 7 3}$ & $\mathbf{0 . 5 3 6}$ & $\mathbf{0 . 6 3 3}$ \\
P. oceanica & $\mathbf{0 . 3 6 7}$ & $\mathbf{- 0 . 7 9 2}$ & 0.175 \\
Sedimentary bottoms & 0.017 & 0.237 & $\mathbf{- 0 . 6 0 4}$ \\
Cumulative percent of explained variation & 63.6 & 83.4 & 95.0 \\
\hline
\end{tabular}


unlikely to provide insight into the potential factors underlying the spread of this seaweed.

In contrast, relatively large values of cover of Caulerpa racemosa (>10\%) were frequent on reefs along the coast of Tuscany, warranting further analysis. The model was initially fitted specifying a Poisson error structure, but inspection of the residuals showed overdispersion. Since this could not be mitigated by using a quasi-Poisson or a negative binomial error distribution, we log transformed the response variable and fitted a model with error structure based on the normal distribution and an identity link. Model validation excluded the need to model spatial autocorrelation further (i.e. inspection of residuals did not display any evidence of spatial autocorrelation) and showed that the assumption of linearity and homogeneity of variances were met.

The minimum adequate models (MAM) were generated by means of a step-forward routine (forward.lmer function developed by R. Nieuwenhuis), using the Akaike information criterion (Burnham \& Anderson 2002). This model contains the minimum number of variables for which no addition or deletion of any variable increases its explanatory power. The amount of variance in the response variable captured by each simplified model was assessed as the percent deviance explained $(\% \mathrm{DE})$, calculated in relation to the deviance of the null model retaining the hierarchical random effect structure, but no fixed effects (i.e. intercept only model).

The individual contribution of each predictor variable in the model was assessed by quantifying the decrease in \%DE generated by deleting each variable from the full model (i.e. the model including all variables) and the increase generated by including each variable to the null model (Ohlemüller et al. 2006).

\section{RESULTS}

\section{Coast of Tuscany}

A total of 274 , out of the 480 plots $(\sim 57 \%)$, sampled across urban, extra-urban and off-shore reefs along the coast of Tuscany, were colonized by Caulerpa racemosa. The base model accounted for $0.74 \%$ of the deviance $(\% \mathrm{DE})$, suggesting that human influence has little effect on patterns of distribution of C. racemosa along this coast. Adding 13 covariates to the base model resulted in a considerable increase in the percentage of explained deviance (full model \%DE = 25.82). The MAM, retaining only 5 covariates (Table 2A), accounted for a similar proportion of explained deviance $(24.58 \%)$. When variation due to habitat quality and features of benthic assemblages was taken into account (Table 2A), the proportion of plots colonized by the seaweed on urban reefs $(60.62 \%)$ was significantly greater than that on extraurban reefs $(48.75 \%)$, but similar to that on off-shore reefs $(56.25 \%)$.

Patterns of distribution of Caulerpa racemosa were regulated by features of both habitat and benthic assemblages (Table 2A, Fig. 2A). The probability of detecting the seaweed was smaller in seagrass meadows or on coralligenous surfaces, while it was greater where space was monopolized by algal turfs or dead matte, as shown by the negative and positive estimate signs of PC1 and PC3, respectively (Tables 1A \& 2A for interpreting the meaning of PCA axes).

Macroalgal diversity (i.e. number of macroalgal taxa) was the variable accounting most for variation in the distribution of Caulerpa racemosa (Fig. 2A). In particular, the colonization by $C$. racemosa was more likely where macroalgal assemblages were characterized by great diversity or large values of total cover. In contrast, it was reduced in plots hosting more diverse sessile invertebrate assemblages (Table 2A, Fig. 2A).

The percentage cover (means $\pm \mathrm{SE}$ ) of Caulerpa racemosa tended to be greater in urban $(6.50 \pm 0.81)$ than in extra-urban $(3.10 \pm 0.81)$ or off-shore reefs $(3.31 \pm 0.81$; SE are calculated as the square root of ratios between the mean square of the natural denominator for testing the main effect of human influence in a classical ANOVA test and the number of observations used to calculate treatment means, to provide a pooled estimate of the variation among subgroups; Winer et al. 1991, Underwood 1997). The base model accounted for a small amount of deviance $(0.35 \%)$ and did not detect differences among areas subjected to different human influences. The inclusion of the whole set of covariates generated an increase in the percentage of explained deviance of about $15 \%$ (full model $\% \mathrm{DE}=15.48$ ). Deletion of variables through a step-forward procedure did not cause a significant loss of explained deviance $(15.17 \%)$, confirming that eliminated variables had negligible effects on the cover of C. racemosa.

Most of the covariates describing habitats and assemblages that accounted for variation in the presence of Caulerpa racemosa also played a comparable role in determining variation in its cover (Table 2B). Again, the first and third axes generated by the PCA had a significant effect that was negative and positive, respectively. Thus, the cover of C. racemosa also tended to be greater in patches dominated by algal turfs or dead matte than in those monopolized by intact seagrass beds or coralligenous assemblages (see Table 1A for interpreting the meaning of PCA axes). In addition, a significant positive effect of the RCI suggests that $C$. racemosa attained greater cover values in seascapes 
Table 2. Caulerpa racemosa. Generalized linear mixed-effects models investigating correlates of: (A) colonization (estimated as presence/absence) and (B) abundance (estimated as percentage cover) of C. racemosa on urban, extra-urban and off-shore rocky reefs along the coast of Tuscany. Coefficients, standard errors (SE) and p-values for variables retained in the minimum adequate model (MAM) are reported for fixed effects, while estimates of the variance $\left(\sigma^{2}\right)$ and standard deviations (SD) are reported for random effects. For levels of human influence, estimates represent the direction and magnitude of the variation in relation to the urban level. AIC: Akaike information criterion; PC: principal component; RCI: relative contagion index

\begin{tabular}{|c|c|c|c|c|}
\hline Effect & Variable category & $\begin{array}{c}\text { Estimate } \\
\text { or } \sigma^{2}\end{array}$ & $\begin{array}{l}\text { SE or } \\
\text { SD }\end{array}$ & $\mathrm{p}$ \\
\hline \multicolumn{5}{|c|}{ (A) MAM model: presence/absence $(\mathrm{AIC}=427.1)$} \\
\hline \multicolumn{2}{|c|}{ Fixed effects } & Estimate & $S E$ & \\
\hline \multicolumn{2}{|l|}{ Intercept } & -4.520 & 0.851 & $<0.001$ \\
\hline Extra-urban reefs & Human influence & -1.525 & 0.754 & $<0.05$ \\
\hline Off-shore reefs & Human influence & 0.444 & 0.165 & $>0.05$ \\
\hline PC1 & Habitat quality & -0.046 & 0.007 & $<0.001$ \\
\hline PC3 & Habitat quality & 0.047 & 0.014 & $<0.001$ \\
\hline Invertebrate diversity & Benthic assemblage structure & -0.578 & 0.142 & $<0.001$ \\
\hline Macroalgal diversity & Benthic assemblage structure & 0.646 & 0.091 & $<0.001$ \\
\hline Macroalgal cover & Benthic assemblage structure & 0.016 & 0.008 & $<0.05$ \\
\hline \multicolumn{2}{|l|}{ Random effects } & $\sigma^{2}$ & $S D$ & \\
\hline \multicolumn{2}{|l|}{ Site } & 0.000 & 0.000 & \\
\hline \multicolumn{2}{|c|}{ Area(Site) } & 0.440 & 0.663 & \\
\hline & 0.925 & 0.962 & \\
\hline & & \multicolumn{3}{|c|}{ AIC base model $=548.7 ;$ AIC full model $=436.4$} \\
\hline \multicolumn{5}{|c|}{ (B) MAM model: percentage cover $(\mathrm{AIC}=394.3)$} \\
\hline \multicolumn{2}{|c|}{ Fixed effects } & Estimate & $S E$ & \\
\hline \multicolumn{2}{|l|}{ Intercept } & -0.263 & 0.206 & $>0.05$ \\
\hline Extra-urban reefs & Human influence & -0.093 & 0.092 & $>0.05$ \\
\hline Off-shore reefs & Human influence & 0.097 & 0.095 & $>0.05$ \\
\hline PC1 & Habitat quality & -0.004 & 0.001 & $<0.001$ \\
\hline PC3 & Habitat quality & 0.009 & 0.002 & $<0.001$ \\
\hline $\mathrm{RCI}$ & Habitat structure & 0.661 & 0.293 & $<0.05$ \\
\hline Invertebrate diversity & Benthic assemblage structure & -0.060 & 0.016 & $<0.001$ \\
\hline Macroalgal diversity & Benthic assemblage structure & 0.043 & 0.008 & $<0.001$ \\
\hline Random effects & & $\sigma^{2}$ & $S D$ & \\
\hline Site & & 0.000 & 0.000 & \\
\hline Area(Site) & & 0.000 & 0.000 & \\
\hline Transect[Area(Site)] & & 0.045 & 0.212 & \\
\hline Residual & & 0.107 & 0.328 & \\
\hline AIC base model $=449$. & $0 ;$ AIC full model $=407.4$ & & & \\
\hline
\end{tabular}

decreased significantly when moving towards the lower end of the human disturbance gradient (urban reefs: $78.75 \%$; extra-urban: $37.5 \%$; totally protected reefs: $1.25 \% ; \mathrm{n}=$ 80). Indeed, human influence was the variable accounting most for variations in the distribution of $C$. racemosa (Fig. 3A). The MAM, retaining only 2 covariates, the depth and invertebrate diversity, with a DE\% of 17.1, produced an increase of $\sim 9 \%$ in relation to the base model (Table 3A). Coefficient estimates were negative for both covariates, indicating that plots at shallow depths and those characterized by greater richness of invertebrate taxa were less likely to be colonized by $C$. racemosa (Table 3A).

\section{Capraia Island}

At Capraia Island, a small proportion of sampled plots was colonized by Caulerpa racemosa, both on totally protected $(17.5 \%$; $\mathrm{n}=$ 80) and partially protected reefs $(12.5 \% ; n=80)$. Accordingly, the analysis did not reveal significant differences between levels of protection (i.e. human influence; Table $3 \mathrm{~B})$. The MAM including the second PCA axis (PC2) and macroalgal diversity generated an increase of $18.84 \%$ in $\mathrm{DE}$, in relation to the base model (Table 3B). Such an increase was comparable to that produced by adding the entire set made of few large, contiguous habitat patches rather than small and scattered ones (Table 2B).

Likewise, at the community level, the cover of Caulerpa racemosa was correlated positively to the diversity of macroalgae and negatively to that of sessile invertebrates (Table 2B). Macroalgal diversity had the greatest individual explanatory power of the entire set of covariates retained in the MAM (Fig. 2B).

\section{NW Sardinia}

Along the north-western tip of Sardinia, the proportion of sampled plots colonized by Caulerpa racemosa 23.02). Macroalgal diversity had the greatest explanatory power for the distribution of $C$. racemosa on reefs at Capraia Island (Fig. 3B). In accordance with the analyses of data from the coast of Tuscany, the presence of $C$. racemosa was positively correlated to the diversity of macroalgal assemblages. Along with such community level effects, the distribution of C. racemosa was also influenced by habitat quality (Table 3B). In particular, seaweed colonization was positively and negatively correlated to the relative extent of patches colonized by dead matte or living plants of $P$. oceanica, respectively (see Table $1 \mathrm{C}$ for interpreting the meaning of PCA axes). of covariates to the base model (full model \%DE = 
A Presence/Absence

Delete contribution Add contribution

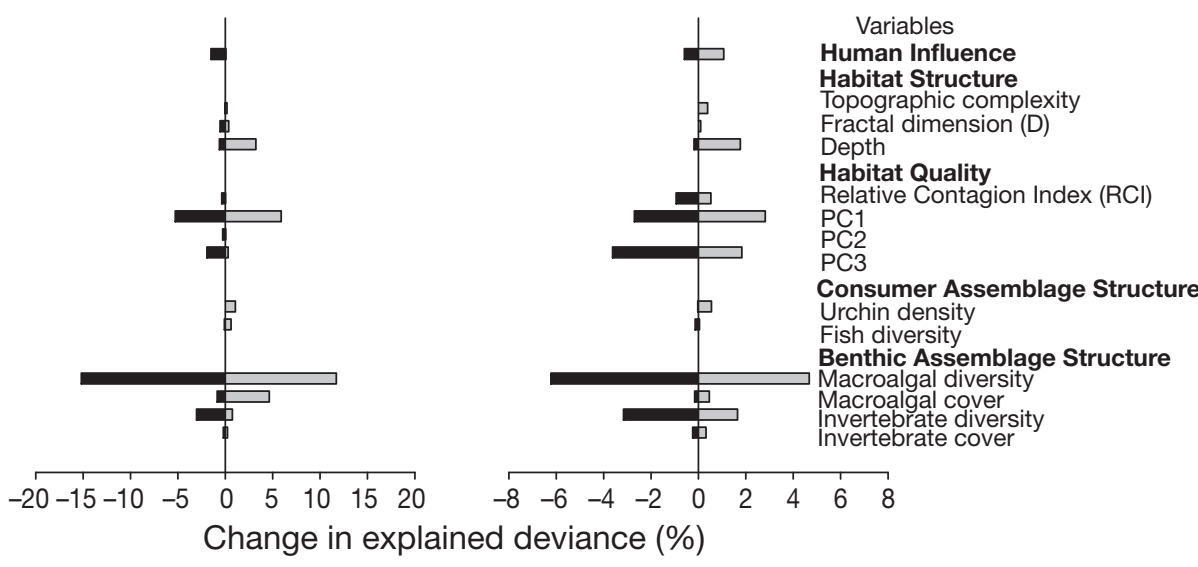

Fig. 2. Caulerpa racemosa. Changes in percentage explained deviance generated by the deletion of individual variables from maximal models (delete contribution) and by the addition to the null model (add contribution), separately for the: (A) presence/absence and (B) percentage cover of $C$. racemosa along the coast of Tuscany. PC: principal component

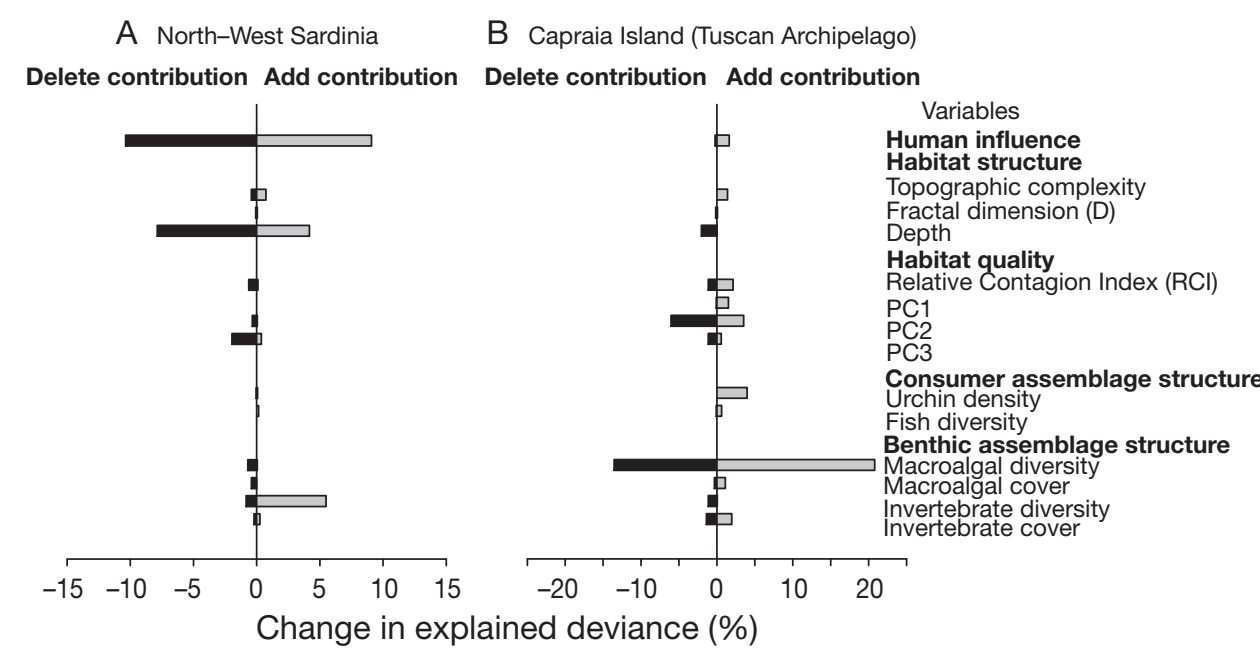

Fig. 3. Caulerpa racemosa. Change in percentage explained deviance generated by the deletion of individual variables from maximal models (delete contribution) and by the addition to the null model (add contribution), separately for the presence/absence of C. racemosa in: (A) NW Sardinia and (B) at Capraia Island

\section{DISCUSSION}

Theory predicts that disturbance can promote ecosystem invasion, by reducing the intensity of competition for resources from extant assemblages (Hobbs \& Huenneke 1992, Davis et al. 2000). In accordance, urban environments, being generally characterized by large propagule pressure and high levels of human disturbance, are thought to be particularly susceptible to invasion (Glasby et al. 2006, Pickett et al. 2008, Clark \& Johnston 2009). Our results support these predictions, showing that major alterations to physical and biological conditions are likely to enhance the local spread of Caulerpa racemosa.

Interpreting patterns of distribution of Caulerpa racemosa across areas influenced by different human activities initially requires an understanding of variations among alternative habitats. In accordance with the findings of previous manipulative (Ceccherelli et al. 2000, Bulleri \& Benedetti-Cecchi 2008, Bulleri et al. 2009, 2010) and descriptive studies (Ruitton et al. 2005, Katsanevakis et al. 2010), our analyses reveal that the spread of C. racemosa across heterogeneous seascapes could be hindered by intact stands of canopy-forming macroalgae and seagrass meadows and fostered by degraded habitats, such as those formed by algal turfs or Posidonia oceanica dead matte. Importantly, this clearly shows that patterns of distribution of C. racemosa on rocky bottoms are dependent upon the characteristics of dominant macroalgae (i.e. encrusting corallines, turf-, or canopy-forming) and that their grouping into a single habitat type (e.g. rocky bottoms; Katsanevakis et al. 2010) is likely to yield little predictive power.

Habitat loss and degradation are widespread along coasts influenced by human activities, such as urbanization, agriculture and deforestation (Airoldi \& Beck 2007). For instance, inputs of nutrients or terrigenous 
Table 3. Caulerpa racemosa. Generalized linear mixed-effects model investigating correlates of the colonization (estimated as presence/absence) of C. racemosa on: (A) urban, extra-urban and totally protected reefs in north-western Sardinia and (B) totally versus partially protected reefs at Capraia Island (Tuscan archipelago). Coefficients, standard errors (SE) and p-values for variables retained in the minimum adequate model (MAM) are reported for fixed effects, while estimates of the variance $\left(\sigma^{2}\right)$ and standard deviations (SD) are reported for random effects. For levels of human influence, estimates represent the direction and magnitude of the variation in relation to the urban level for NW Sardinia and to the partially protected reef level for Capraia Island. AIC: Akaike information criterion; PC: principal component

\begin{tabular}{|c|c|c|c|c|}
\hline Effect & Variable category & $\begin{array}{l}\text { Estimate } \\
\text { or } \sigma^{2}\end{array}$ & $\begin{array}{l}\text { SE or } \\
\text { SD }\end{array}$ & $\mathrm{p}$ \\
\hline \multicolumn{5}{|c|}{ (A) MAM model: NW Sardinia (AIC $=171.1)$} \\
\hline \multicolumn{2}{|c|}{ Fixed effects } & Estimate & $S E$ & \\
\hline \multicolumn{2}{|l|}{ Intercept } & 8.328 & 2.604 & $<0.01$ \\
\hline Extra-urban reefs & Human influence & -4.200 & 1.298 & $<0.01$ \\
\hline Totally protected reefs & Human influence & -8.725 & 2.117 & $<0.001$ \\
\hline Depth & Not applicable & -0.760 & 0.313 & $<0.05$ \\
\hline Invertebrate diversity & Benthic assemblage structure & -2.776 & 1.343 & $<0.05$ \\
\hline \multicolumn{2}{|l|}{ Random effects } & $\sigma^{2}$ & $S D$ & \\
\hline \multicolumn{2}{|l|}{ Area } & 0.412 & 0.203 & \\
\hline \multirow{2}{*}{\multicolumn{2}{|c|}{$\begin{array}{l}\text { Transect(Area) } \\
\text { AIC base model }=182.1 ; \text { AIC full model }=177.8\end{array}$}} & 0.000 & 0.000 & \\
\hline \multirow{2}{*}{\multicolumn{5}{|c|}{ (B) MAM model: Capraia Island $($ AIC = 111.2) }} \\
\hline & & & & \\
\hline \multicolumn{2}{|c|}{ Fixed effects } & Estimate & $S E$ & \\
\hline \multicolumn{2}{|l|}{ Intercept } & -6.614 & 1.481 & $<0.001$ \\
\hline Totally protected reefs & Human influence & 0.427 & 1.132 & $>0.05$ \\
\hline $\mathrm{PC} 2$ & Habitat quality & 0.077 & 0.024 & $<0.01$ \\
\hline Macroalgal diversity & Benthic assemblage structure & 0.530 & 0.148 & $<0.001$ \\
\hline \multicolumn{2}{|l|}{ Random effects } & $\sigma^{2}$ & $S D$ & \\
\hline \multicolumn{2}{|l|}{ Area } & 0.897 & 0.947 & \\
\hline \multicolumn{2}{|c|}{ Transect(Area) } & 0.250 & 0.500 & \\
\hline \multicolumn{5}{|c|}{ AIC base model $=130.2 ;$ AIC full model $=121.1$} \\
\hline
\end{tabular}

of C. racemosa among areas subjected to different prevailing human influences (Fig. A1).

When this background noise was filtered out by including habitat and assemblage descriptors, significant variation in the distribution of Caulerpa racemosa emerged between urban and extra-urban reefs. The inclusion of covariates did not, however, unmask variations in local patterns of distribution of C. racemosa between urban and offshore reefs. The latter are probably less affected by land-based human disturbances, such as inputs of organic and inorganic pollutants or terrigenous sediments, in comparison to coastal reefs (Balata et al. 2007a). However, these shallow water reefs attract recreational boaters, anglers and artisanal fishermen (i.e. 100s of boats per day in summer; F. Bulleri pers. obs.). As a consequence, levels of mechanical disturbance due to anchoring and fishing gear might be greater here than on more coastal reefs. The damage thereby produced to habitats conferring resistance to invasion (i.e. seagrass beds and stands of canopy-forming macroalgae) would ultimately foster the spread

sediments have been shown to cause the replacement of canopy-forming macroalgae by stress-tolerant algal turfs (Gorman \& Connell 2009). In addition to poor water quality, mechanic disturbance due to dredging, trawling, or boating (i.e. anchoring and propeller scarring) can contribute to the decline of seagrass beds (Orth et al. 2006). Thus, multiple stressors, operating either separately or in concert, can promote habitat degradation in shallow coastal waters.

In NW Sardinia, patterns of occurrence of Caulerpa racemosa among areas subjected to different human influences were matched to variations in the relative proportion of favourable and unfavourable habitats (Fig. A1 in Appendix 1). For instance, dead Posidonia oceanica matte and algal turfs represented $>80 \%$ of shallow water habitats in urban areas, but were poorly represented on protected reefs. In contrast, along the coast of Tuscany, stands of turf-forming macroalgae were, by far, the most common habitat and there were not clear-cut differences in the relative proportion of habitats or in the characteristics of assemblages influencing (either positively or negatively) the occurrence of C. racemosa, despite overall environmental conditions being not severely degraded. This indicates that prevailing human influences are not always good predictors of invasibility when considered as a whole. More accurate predictions are likely generated by models accounting for habitat- or assemblage-specific effects of different forms of disturbance, in relation to life-history traits of potential invaders. water habitats, such as that generated by the exclusion of human activities, does not guarantee a barrier against invasion by Caulerpa racemosa, in accordance with patterns reported by Katsanevakis et al. (2010) for the Ionian Sea. Although to a different extent, C. racemosa was found in areas where human activities are totally banned, both in NW Sardinia (Asinara Island MPA) and the Tuscan archipelago (Capraia Island MPA).

In these relatively well preserved systems, Caulerpa racemosa is not, however, a common component of benthic communities. At a landscape scale, such decreased success might be the outcome of a limited sup-
A dramatic abatement of disturbance in shallow 
ply of fragments of the alga, coupled with a greater proportion of habitats intrinsically more resistant to invasion. For instance, Posidonia oceanica beds and canopy-forming algal stands were dominant along the coasts of the Asinara (cumulative proportion: 90\%) and Capraia Islands (cumulative proportion: $~ 66$ and $50 \%$ on partially and totally protected reefs, respectively). In contrast, habitats highly susceptible to invasion were poorly represented or indeed absent (i.e. dead P. oceanica matte at Asinara Island) within these MPAs (Fig. A1).

The regional approach of our study enables drawing a general picture of patterns of distribution of Caulerpa racemosa along gradients of human disturbance. Reefs in front of urban developments or industrial plants face the upper levels of such a gradient. Here, severe degradation of habitats (i.e. dominance of algal turfs and/or dead Posidonia oceanica matte) would favour the establishment and diffusion of C. racemosa. Habitat degradation is, however, not limited to reefs in front of major urban or industrial centres, but propagates to extra-urban coasts and, likely through the action of different sources of disturbance, to off-shore reefs (Fig. A1). In these areas, the availability of suitable degraded habitats is generally large enough to enable the local diffusion of C. racemosa. In accordance, the abatement of human disturbance (either partial or total), promoting the persistence of seagrass and canopy-forming macroalgal stands, hastens the diffusion of C. racemosa. At Capraia Island, the total banning of human activities does not generate an increment in the occurrence of unfavourable habitat to $C$. racemosa in respect to partial protection and, hence, in resistance to invasion (Fig. A1). However, when total protection promotes the monopolization of space by seagrass and canopy-forming species, as in the case of the MPA investigated in NW Sardinia, the diffusion of C. racemosa can almost be halted (Fig. A1).

On rocky reefs lacking large patches dominated by algal turfs or dead matte, such as those found at Capraia Island, the probability of colonization by Caulerpa racemosa was positively correlated to the proportion of coralligenous surfaces. In contrast, in more disturbed environments (i.e. the coast of Tuscany), there was a negative correlation between the relative abundance of coralligenous surfaces and the presence of the invader. Thus, coralligenous surfaces, although not representing the most suitable habitats for C. racemosa, are likely to be the least resistant to invasion on well-preserved rocky reefs. C. racemosa can form dense mats on coralligenous surfaces, at depths greater (i.e. 15 to $50 \mathrm{~m}$ ) than those encompassed by the present study (Piazzi et al. 2007, Baldacconi \& Corriero 2009). This suggests that habitat protection is not a panacea against invasion by C. race- mosa. Nonetheless, preserving valuable habitats, such as those formed by architecturally complex macroalgae or seagrasses, would be effective in reducing the spread of this invader in shallow waters (Bulleri et al. 2010, Katsanevakis et al. 2010).

Our analyses did not detect a significant correlation between habitat configuration and distribution of Caulerpa racemosa. These results are in accordance with those of Katsanevakis et al. (2010), who found no significant correlation between the size of gaps within Posidonia oceanica beds and the presence of C. racemosa and suggest that this seaweed is able to colonize patches of suitable habitats, regardless of their extension and spatial arrangement.

However, along the coast of Tuscany, Caulerpa racemosa attained a greater extent of cover when the landscape was made of a few large and contiguous habitat patches than when it was composed by small and scattered ones. Fragmentation fosters or hinders the spread of an invader when the matrix (i.e. the dominant type of habitat) being disturbed is formed by an unsuitable or suitable habitat, respectively (With 2002). Along the coast of Tuscany, the matrix was predominantly made of favourable habitat types (algal turfs and dead matte). The margins of invasionresistant habitats can accumulate fragments of exotic species (Ceccherelli et al. 2000, Katsanevakis et al. 2010) by acting as current-breakers. Nonetheless, the ability of C. racemosa to grow and conquer space is probably greater in the interior of patches of favourable habitats, where the influence of surrounding unfavourable habitats is reduced.

At a finer spatial scale than that of the landscape, the spread of Caulerpa racemosa was correlated to features of benthic assemblages. Consistently across areas investigated, the probability of $C$. racemosa to be present in a plot was positively correlated to the diversity of the native macroalgal assemblage and negatively to that of the sessile invertebrate assemblage. In addition, where macroalgal assemblages were mainly composed by turfing forms (i.e. along the coast of Tuscany), the probability of finding C. racemosa in a plot increased with macroalgal cover. Overall, this suggests that the ability of C. racemosa to acquire space could be greater where macroalgae dominate benthic assemblages at the expense of sessile invertebrates. These patterns match well those that emerged at the landscape level, since Posidonia oceanica and canopyforming macroalgae, being important habitat formers, generally support more diverse sessile invertebrate assemblages than degraded habitats (Bulleri et al. 2002, Balata et al. 2007b).

Invertebrate assemblages were mainly composed by tube-dwelling gastropods (Vermetus triqueter), polychaetes (spirorbids) and encrusting sponges. Retention 
and anchoring of fragments of Caulerpa racemosa on these surfaces could be smaller than within the complex 3-dimensional matrix formed by algal turfs (Ceccherelli et al. 2002, Bulleri \& Benedetti-Cecchi 2008). As mentioned previously, C. racemosa is able to colonize coralligenous assemblages dominated by sponges (Baldacconi \& Corriero 2009), but at depths where hydrodynamic stress is weaker and the need to gain a firm hold to the substratum is less pressing. The negative relationship between $C$. racemosa and the depth emerged in NW Sardinia confirms a certain susceptibility of this species to wave stress.

Conflicting results have emerged between smallscale experimental studies, reporting a negative relationship between native and exotic species richness (Levine 2000, Kennedy et al. 2002, Stachowicz et al. 2002) and large-scale descriptive studies (Stohlgren et al. 1999, Levine 2000), documenting a positive relationship. A positive correlation between native and exotic diversity at large spatial scales would be generated by a similar response of native and exotic species to heterogeneity in abiotic factors that generally increase with spatial scale (Shea \& Chesson 2002). Here, both native macroalgal richness and presence or cover of C. racemosa was quantified at a relatively small spatial scale (i.e. $20 \times 20 \mathrm{~cm}$ quadrat). Nonetheless, due to the dominance of small-sized organisms, these sampling units could have been large enough to sample most of the native species and, hence, to include those functional traits facilitating C. racemosa. At increasing levels of diversity, negative effects due to pre-emption of resources might be overcompensated for by the greater probability of including species that possess traits conferring on them the ability to facilitate invaders (Bulleri et al. 2008).

The structure of higher trophic levels resulted in a poor predictor of patterns of distribution and abundance for Caulerpa racemosa. This does not imply that the effects of organisms at higher trophic levels on the colonization or spread of C. racemosa should be ruled out, but rather suggests that the influence of features of benthic habitats and assemblages might be overarching. On the other hand, the large natural temporal variability in the structure of consumer guilds, in particular of fish assemblages, might underlie the limited power of these variables to predict the distribution of C. racemosa.

In conclusion, Caulerpa racemosa is able to take advantage of degradation of habitats and benthic assemblages by human activities. Although unlikely to prevent colonization, preserving and/or restoring habitats, such as those dominated by Posidonia oceanica and canopy-forming macroalgae, might effectively reduce the ability of $C$. racemosa to achieve dominance and advance to an invasive status and, hence, to minimize alterations to native biodiversity. Finally, our findings warn against the over-simplistic assumption of greater success of C. racemosa in areas closer to human or industrial conglomerates. In fact, predicting locales more susceptible to invasion not only requires a deep knowledge of the structure of the ecosystems being threatened at a hierarchy of levels of biological organization (from the landscape down to the assemblage), but also detailed information on the nature and intensity of potential sources of disturbance and of the spatial scales at which they operate.

Acknowledgements. We sincerely thank I. Bertocci and C. Cristaudo for help with fieldwork, B. Padedda for drawing the map of study sites and 4 anonymous reviewers for offering valuable comments. This work was supported by the University of Pisa through the project Bioclima and by the MIUR through the project BIORES. Many thanks to G. Fissore (Assonautica Livorno) for assisting with boating operations. S.P. was supported by funds from a 'Regione Autonoma Sardegna' (PO Sardegna FSE2007-2013 LR7/2007) grant.

\section{LITERATURE CITED}

Airoldi L, Beck MW (2007) Loss, status and trends for coastal marine habitats of Europe. Oceanogr Mar Biol Annu Rev 45:345-405

Balata D, Piazzi L, Benedetti-Cecchi L (2007a) Sediment disturbance and loss of beta diversity on subtidal rocky reefs. Ecology 88:2455-2461

Balata D, Nesti U, Piazzi L, Cinelli F (2007b) Patterns of spatial variability of seagrass epiphytes in the north-west Mediterranean Sea. Mar Biol 151:2025-2035

Baldacconi R, Corriero G (2009) Effects of the spread of the alga Caulerpa racemosa var. cylindracea on the sponge assemblage from coralligenous concretions of the Apulian coast (Ionian Sea, Italy). PSZN I: Mar Ecol 30:337-345

Ballesteros E (2006) Mediterranean coralligenous assemblages: a synthesis of present knowledge. Oceanogr Mar Biol Annu Rev 44:123-195

Box A, Deudero S, Sureda A, Blanco A and others (2009) Diet and physiological responses of Spondyliosoma cantharus (Linnaeus, 1758) to the Caulerpa racemosa var. cylindracea invasion. J Exp Mar Biol Ecol 380:11-19

Bruno JF, Bertness MD (2001) Habitat modification and facilitation in benthic marine communities. In: Bertness MD, Gaines SD, Hay ME (eds) Marine community ecology. Sinauer, Sunderland, p 201-218

Bulleri F, Benedetti-Cecchi L (2008) Facilitation of the introduced green alga, Caulerpa racemosa, by resident algal turfs: experimental evaluation of underlying mechanisms. Mar Ecol Prog Ser 364:77-86

Bulleri F, Benedetti-Cecchi L, Acunto S, Cinelli F, Hawkins SJ (2002) The influence of canopy algae on vertical patterns of distribution of low-shore assemblages on rocky coasts in the northwest Mediterranean. J Exp Mar Biol Ecol 267: 89-106

Bulleri F, Bruno JF, Benedetti-Cecchi L (2008) Beyond competition: incorporating positive interactions between species to predict ecosystem invasibility. PLoS Biol 6:e162

> Bulleri F, Tamburello L, Benedetti-Cecchi L (2009) Loss of consumers alters the effects of resident assemblages on 
the local spread of an introduced macroalga. Oikos 118: 269-279

Bulleri F, Balata D, Bertocci I, Tamburello L, Benedetti-Cecchi L (2010) The seaweed Caulerpa racemosa on Mediterranean rocky reefs: from passenger to driver of ecological change. Ecology 91:2205-2212

Burnham KP, Anderson DR (2002) Model selection and multimodel inference. Springer, New York, NY

Byers JE (2002) Physical habitat attribute mediates biotic resistance to non-indigenous species invasion. Oecologia 130:146-156

> Ceccherelli G, Piazzi L, Cinelli F (2000) Response of the nonindigenous Caulerpa racemosa (Forsskal) J. Agardh to the native seagrass Posidonia oceanica (L.) Delile: effect of density of shoots and orientation of edges of meadows. J Exp Mar Biol Ecol 243:227-240

Ceccherelli G, Piazzi L, Balata D (2002) Spread of introduced Caulerpa species in macroalgal habitats. J Exp Mar Biol Ecol 280:1-11

Clark GF, Johnston EL (2009) Propagule pressure and disturbance interact to overcome biotic resistance of marine invertebrate communities. Oikos 118:1679-1686

Crawley MJ (2002) Statistical computing: an introduction to data analysis using S-Plus. Wiley, Chichester

Crawley MJ (2007) The R book. Wiley, Chichester

Davis MA, Grime JP, Thompson K (2000) Fluctuating resources in plant communities: a general theory of invasibility. J Ecol 88:528-534

Diez JM, Buckley HL, Case BS, Harsch MA, Sciligo AR, Wangen SR, Duncan RP (2009) Interacting effects of management and environmental variability at multiple scales on invasive species distributions. J Appl Ecol 46:1210-1218

> Dupré C, Ehrlén J (2002) Habitat configuration, species traits and plant distributions. J Ecol 90:796-805

Glasby TM, Connell SD, Holloway MG, Hewitt CL (2006) Nonindigenous biota on artificial structures: Could habitat creation facilitate biological invasions? Mar Biol 151: 887-895

> Gorman D, Connell SD (2009) Recovering subtidal forests in human-dominated landscapes. J Appl Ecol 46:1258-1265

Guidetti P (2007) Potential of marine reserves to cause community-wide changes beyond their boundaries. Conserv Biol 21:540-545

Hastings A, Cuddington K, Davies KF, Dugaw CJ and others (2005) The spatial spread of invasions: new developments in theory and evidence. Ecol Lett 8:91-101

Hobbs RJ, Huenneke LF (1992) Disturbance, diversity, and invasion: implications for conservation. Conserv Biol 6: 324-337

Katsanevakis S, Issaris Y, Poursanidis D, Thessalou-Legaki M (2010) Vulnerability of marine habitats to the invasive green alga Caulerpa racemosa var. cylindracea within a marine protected area. Mar Environ Res 70:210-218

Kennedy TA, Naeem S, Howe KM, Knops JMH, Tilman D, Reich P (2002) Biodiversity as a barrier to ecological invasion. Nature 417:636-638

Kolar CS, Lodge DM (2001) Progress in invasion biology: predicting invaders. Trends Ecol Evol 16:199-204

> Levine JM (2000) Species diversity and biological invasions: relating local process to community pattern. Science 288 : 852-854

Li H, Reynolds JF (1993) A new contagion index to quantify spatial patterns of landscapes. Landsc Ecol 8:155-162

> Loewenstein NJ, Loewenstein EF (2005) Non-native plants in the understory of riparian forests across a land-use gradient in the southeast. Urban Ecosyst 8:79-91

Luckhurst BE, Luckhurst K (1978) Analysis of the influence of substrate variables on coral reef fish communities. Mar Biol 49:317-323

OECD (Organisation for Economic Co-operation and Development) (2002) OECD environmental performance reviews: Italy 2002. OECD Publishing, Paris

> Ohlemüller R, Walker S, Wilson JB (2006) Local vs regional factors as determinants of the invasibility of indigenous forest fragments by alien plant species. Oikos 112:493-501

Orth RJ, Carruthers TJB, Dennison WC, Duarte CM and others (2006) A global crisis for seagrass ecosystems. Bioscience 56:987-996

Piazzi L, Cinelli F (1999) Development and seasonal dynamics of a population of the tropical alga Caulerpa racemosa (Forsskål) J. Agardh in the Mediterranean. Cryptogam Algol 20:295-300

Piazzi L, Meinesz A, Verlaque M, Akçali B and others (2005) Invasion of Caulerpa racemosa var. cylindracea (Caulerpales, Chlorophyta) in the Mediterranean Sea: an assessment of the spread. Cryptogam Algol 26:189-202

Piazzi L, Balata D, Cinelli F (2007) Invasions of alien macroalgae in Mediterranean coralligenous assemblages. Cryptogam, Algol 28:289-301

> Pickett STA, Cadenasso ML, Grove JM, Groffman PM and others (2008) Beyond urban legends: an emerging framework of urban ecology, as illustrated by the Baltimore Ecosystem Study. Bioscience 58:139-150

Pimentel D, McNair S, Janecka J, Wightman J and others (2001) Economic and environmental threats of alien plant, animal, and microbe invasions. Agric Ecosyst Environ 84: $1-20$

Predick KI, Turner MG (2008) Landscape configuration and flood frequency influence invasive shrubs in floodplain forests of the Wisconsin River (USA). J Ecol 96:91-102

R Development Core Team (2010) R: a language and environment for statistical computing. R Foundation for Statistical Computing, Vienna

Richardson DM, Holmes PM, Esler KJ, Galatowitsch SM, and others (2007) Riparian vegetation: degradation, alien plant invasions, and restoration prospects. Divers Distrib 13: $126-139$

Ruitton S, Javel F, Culioli JM, Meinesz A, Pergent G, Verlaque M (2005) First assessment of the Caulerpa racemosa (Caulerpales, Chlorophyta) invasion along the French Mediterranean coast. Mar Pollut Bull 50:1061-1068

Ruitton S, Verlaque M, Aubin G, Boudouresque CF (2006) Grazing on Caulerpa racemosa var. cylindracea (Caulerpales, Chlorophyta) in the Mediterranean Sea by herbivorous fishes and sea urchins. Vie Milieu 56:33-41

Shea K, Chesson P (2002) Community ecology theory as a framework for biological invasions. Trends Ecol Evol 17: $170-176$

Stachowicz JJ, Fried H, Osman RW, Whitlatch RB (2002) Biodiversity, invasion resistance, and marine ecosystem function: reconciling pattern and process. Ecology 83: 2575-2590

> Stohlgren TJ, Binkley D, Chong GW, Klakhan MA and others (1999) Exotic plant species invade hot spots of native plant diversity. Ecol Monogr 69:25-46

Sugihara G, May RM (1990) Applications of fractals in ecology. Trends Ecol Evol 5:79-86

> Terlizzi A, Felline S, Lionetto MG, Caricato R, Perfetti V, Cutignano A, Mollo E (2011) Detrimental physiological effects of the invasive alga Caulerpa racemosa on the Mediterranean white seabream Diplodus sargus. Aquat Biol 12:109-117

- Tomas F, Cebrian E, Ballesteros E (2011) Differential herbivory of invasive algae by native fish in the Mediter- 
ranean Sea. Estuar Coast Shelf Sci 92:27-34

Underwood AJ (1997) Experiments in ecology: their logical design and interpretation using analysis of variance. Cambridge University Press, Cambridge

Von Holle B, Simberloff D (2005) Ecological resistance to biological invasion overwhelmed by propagule pressure. Ecology 86:3212-3218
Winer BJ, Brown DR, Michelis KM (1991) Statistical principles in experimental design, 3rd edn. McGraw-Hill, New York With KA (2002) The landscape ecology of invasive spread. Conserv Biol 16:1192-1203

Zuur AF, Ieno EN, Walker N, Saveliev AA, Smith GM (2009) Mixed effects models and extensions in ecology with R. Springer, New York

Appendix 1.

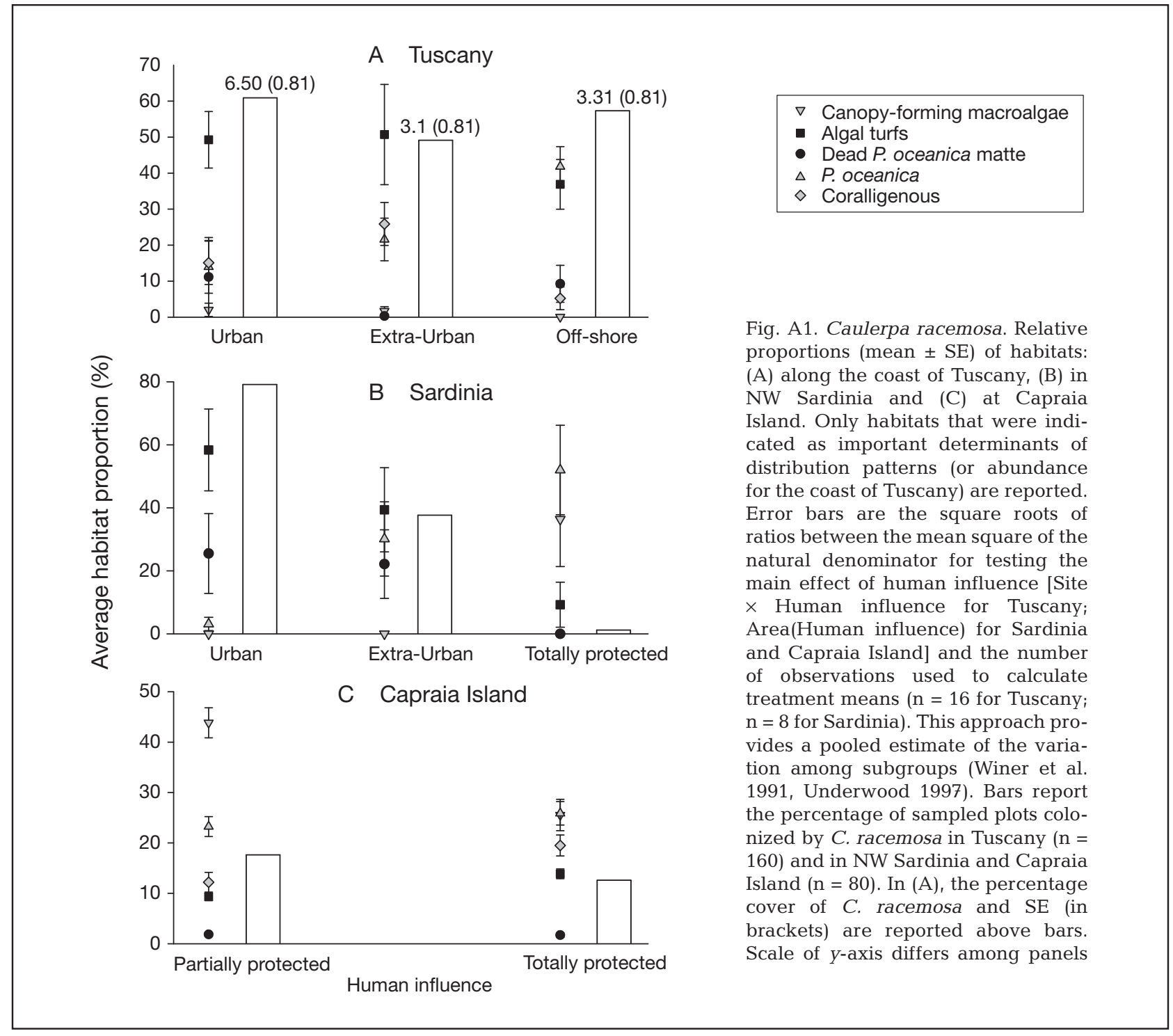

Editorial responsibility: Richard Osman, Edgewater, Maryland, USA
Submitted: October 28, 2010; Accepted: March 18, 2011

Proofs received from author(s): May 18, 2011 